\title{
La crisis entre México y España en el ocaso del franquismo
}

\author{
Marco Antonio Landavazo Arias \\ EL COLEGIO DE MEXXICO
}

\begin{abstract}
A partir de la idea de que entre la política exterior y la interior existen mutuos condicionamientos e influencias, en este artículo se examinan las relaciones entre México

y España al final de la administración del presidente Luis Echeverría Álvarez.
\end{abstract}

\section{INTRODUCCIÓN}

$\mathrm{L}$ a ciencia política ha avanzado en sus postulados teóricos en torno a la relación entre la politica exterior y la política interior de los Estados. Tradicionalmente se consideraba, o bien que la acción internacional de un Estado no era más que la proyección de la política interior más allá de sus fronteras, o bien que la política interna era un factor de la exterior, de tal manera que aquélla aparecía subordinada a ésta. Las propuestas más recientes, en cambio, subrayan el hecho de que no existe una primacía estable- cida de manera inmutable de una u otra política, ya que sus fronteras, sobre todo en la era contemporánea, se han vuelto difusas y permeables. Se ha considerado, así, que se trata de una relación de mutua influencia y condicionamiento y cuya función dentro del marco de la política global no puede definirse por un cierto número de reglas abstractas sino que, más bien, está influida por numerosos factores que son esencialmente cambiantes en la historia de cada Estado. ${ }^{1}$

'Heredia, "Relación", 1986, pp. 115-121; Griepenburg, "Relaciones", 1971, pp. 167-171. 
La forma en que se estructura la política interior y la exterior de un país, en tal virtud, depende de la estructura social y de su constitución política, así como también de su potencial económico, su situación geográfica, el tipo de sus fronteras, sus relaciones con los Estados limítrofes y las grandes potencias, el número de sus habitantes, la opinión pública, la burocracia estatal, etcétera.

En el caso de países como México parece necesario considerar, además, los rasgos especiales que los ubican bajo la categoría genérica de "países en desarrollo" y que, por tal razón, permiten esbozar algunos elementos de caracterización de las relaciones exteriores que les son propias.

Tales elementos son: las limitaciones internas y externas a que se enfrentan al iniciar su vida independiente; las diferencias entre la capacidad y las intenciones de los gobiernos que proveen la medida de su eficacia; la primacía que adquiere la política interior en sus primeras fases como naciones independientes; la resultante debilidad de su política exteriory, por ello, la falta de metas claras; la subordinación económica respecto de las grandes potencias que genera vulnerabilidades internas y externas; la utilización de la política exterior por parte de las elites gubernamentales como instrumento para consolidar su poder; la importancia paulatina que adquieren las necesidades económicas y que las convierte en instancia fundamental para el establecimiento de objetivos en materia internacional; la disminución de la autonomía de los Estados por causa de la interdependencia creciente que

provoca oportunidades para la influencia e intervención del exterior. ${ }^{2}$

México se sitúa dentro de este amplio marco, aunque ciertamente su caso presenta singularidades derivadas de su historia y su posición geográfica. Conviene señalar, cuando menos, una de ellas: la importancia que cobra en México la autoridad de sus presidentes. Si como persona moral el Estado no tiene más voluntad que la de los individuos que detentan el control del mismo, ${ }^{3}$ en México, gracias a un sistema político en el que la pieza fundamental ha sido el presidente y cuyos primeros soportes son constitucionales, la voluntad estatal ha sido a menudo la voluntad presidencial; de alli que se hable de un "estilo personal de gobernar", de obligado carácter sexenal. ${ }^{4}$ En tal suerte, la política exterior mexicana ha sido un campo en el que el "estilo" de cada presidente ha dejado también su impronta.

En este trabajo pretendo describiry analizar un episodio interesante de las relaciones exteriores de México -relacionado con España, en los finales de la administración gubernamental de Luis Echeverría Álvarez-, que permite observar precisamente la manera en que en nuestro país, según determinadas circunstancias históricas y geopolíticas, se relacionan factores exógenos, endógenos y psicológicos en un juego de interdependencias mutuas.

\footnotetext{
2 Heredia, "Relación", 1986, pp. 122-124.

3 Lacharrière, Études, 1964, p. 170.

4 Carpizo, Presidencialismo, 1987; Cosío Villegas, Estilo, 1974.
} 


\section{LA POLITICA EXTERIOR DE ECHEVERRIA}

A principios de siglo y hasta 1940 , la actividad internacional de México persiguió los objetivos tradicionales en materia de seguridad nacional que caracterizaron a las décadas anteriores, pero además trató de aislar al país para consolidar, en el ámbito interno, el naciente poder derivado de la revolución de 1910. A través del principio de la no intervención se trató de mantener relativamente alejado al país del escenario internacional y concentrado en atender los problemas con los vecinos más próximos. Así, la política exterior mantuvo una actitud cautelosa, reservada y discreta, a excepción de casos notables como el de la República Española. Entre 1940 y 1970, los objetivos del desarrollo económico se incorporaron a la agenda de la política exterior, de tal suerte que ésta adquirió la función de promotora externa del crecimiento económico nacional, aunque sustentada básicamente en los mismos lineamientos del periodo inmediato anterior. 5

Con la gestión político-administrativa de Luis Echeverría Álvarez como presidente de la república, se produjo un cambio sustancial en la política exterior, obligado por la conjunción de tres factores que hicieron crisis a fines de la década de los sesenta: 1) El agotamiento de la estrategia de desarrollo económico que el país venía siguiendo, modelo conocido como "desarrollo estabilizador", debido, entre otras razones, a su incapacidad para gene-

5 Heredia, "Relación", 1986, p. 127; Ojeda, Alcances, 1984, pp. 3-31. rar los empleos requeridos por el crecimiento demográfico y para redistribuir equitativamente la riqueza, por el estrechamiento del proceso de sustitución de importaciones, por el déficit creciente en la balanza de pagos y por el círculo vicioso del endeudamiento externo; 2) la creciente pérdida de legitimidad del sistema político y su incapacidad para mantener la cohesión social, que derivó en una política apoyada en la fuerza más que en la negociación, expresada en la matanza de octubre de 1968; 3) las transformaciones que experimentó el sistema internacional a mediados de los sesenta, tras el resquebrajamiento del modelo bipolar de la guerra fría, que llevaron a un replanteamiento de las relaciones entre México y Estados Unidos y a una pérdida de la capacidad negociadora del país derivada de su estratégica vecindad geográfica. ${ }^{6}$

Ante una situación de tal naturaleza, el gobierno echeverrista adoptó una actitud internacional que fue dejando atrás la bilateralidad y la pasividad tradicionales, para dar paso al establecimiento de vínculos multilaterales y un activismo sin precedentes. Resulta revelador lo expresado por el propio presidente en su segundo informe de gobierno: México no podía crecer "en soledad", puesto que nada de lo que ocurriese fuera de sus fronteras le era ajeno; el aislamiento era por tanto "imposible", máxime en una época de "creciente interdependencia". Era necesario entonces "multiplicar e intensificar" las relaciones con "todos los países" y no renunciar "a ningún

${ }^{6}$ Ojeda, ibid., pp. 163-175. 
intercambio" que fuera favorable. Los principios de no intervención y autodeterminación seguirían teniendo una defensa "intransigente"; pero a diferencia de la actitud anterior en que se actuó "con cautela", México debería ahora asumir un papel "más relevante" en el orden internacional. Continuaría practicándose una política exterior "independiente", pero agrupándose "activamente" con el tercer mundo y en especial con América Latina. $^{7}$

Fue gestándose de esa manera una política exterior que, en sus rasgos generales, se desplegó en tres frentes: la ampliación y diversificación de las relaciones internacionales del país; la campaña en pro de un nuevo orden económico internacional y el reconocimiento expreso de la identidad de los intereses básicos de México con los de los países en desarrollo. Así, Echeverría realizó 39 visitas de Estado, se entrevistó con 67 jefes de Estado o de gobierno, asistió a casi todos los foros mundiales y regionales de importancia y elevó el número de naciones con las cuales se sostenían relaciones diplomáticas, de 69 a 131, y se firmaron más de 160 acuerdos o convenios internacionales de cooperación científica, técnica, cultural, económica y comercial; ante diversos organismos se formularon proposiciones concretas, como la Carta de Derechos y Deberes Económicos de los Estados, el Sistema de Cooperación para el Desarrollo del Tercer Mundo, el Siste-

7 "Segundo informe de gobierno, 1972", en Archivo Histórico Diplomático Mexicano, 1990, pp. 19.20. ma Económico Latinoamericano y el Banco Mundial de Alimentos; se impulsaron acuerdos de índole bilateral como los relativos a la salinidad del río Colorado y otros de carácter multilateral como los relacionados con el derecho del mar y el desarme. ${ }^{8}$

Múltiples fueron pues las motivaciones en este cambio que experimentó la política exterior mexicana. La crisis del modelo económico y las relaciones desventajosas del país con las potencias económicas, sobre todo con Estados Unidos, expresadas en los problemas de la imposición de la sobretasa del $10 \%$ a las exportaciones mexicanas en 1971, propició la búsqueda de una diversificación de las relaciones económicas y comerciales, con el objetivo de aumentar las exportaciones e incrementar el flujo de divisas y, en un nivel más amplio, se llevó a cabo la promoción de un nuevo orden económico internacional. EI tercermundismo estuvo asociado a estas circunstancias, pero también a la necesidad de recobrar el prestigio internacional de México y de reforzar las bases del sistema político, debilitadas enormemente en 1968, buscando atraer a ciertos sectores de las clases medias, como el estudiantil, el intelectual y grupos de izquierda. No se puede descartar, además, las motivaciones de índole personal del presidente Echeverría: su carácter, su pasado inmediato como secretario de Gobernación y sus anhelos de trascendencia. ${ }^{9}$

8 Ojeda, Alcances, 1984,pp. 176-202; Valero, "Política", 1979, pp. 77-108; García, Seis años, 1976, pp. 7-64; Rabasa, “Apuntes", 1976, pp. 15 . 25.

9 Chabat, "Condicionantes", 1986, pp. 96. 


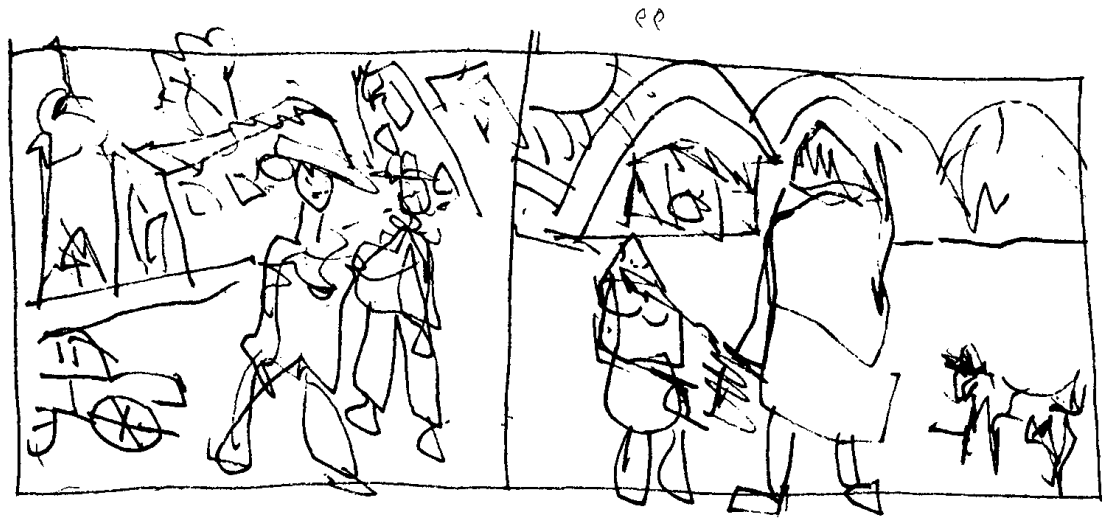

\section{Precedentes Del CONFLiCto}

Es en el marco de esta nueva política exterior, caracterizada por el activismo, el multilateralismo y el tercermundismo, y por la búsqueda de nuevas relaciones internacionales y de la construcción de una nueva imagen del sistema político, tanto en el exterior como en el interior, en que debemos situar los acontecimientos particulares que involucraron a los gobiernos mexicano y español, a finales del año de 1975. Ciertamente, México había mantenido frente a la España de Fran. co, desde Lázaro Cárdenas hasta Gustavo Díaz Ordaz, una actitud conse-

101; Green, "Política", 1977, pp. 4.5; Shapira, "Política", 1978, pp. 62-91. cuente con sus principios básicos de política exterior: la no intervención, la autodeterminación de los pueblos, el apego al derecho internacional y la solidaridad humana. Con el argumento de que el surgimiento del régimen franquista fue producto del apoyo alemán e italiano y, por tanto, violatorio del artículo 10 del Pacto de la Sociedad de Naciones, el gobierno cardenista, en 1939, rompió relaciones con España y reconoció como legítimo al gobierno republicano. Después, en 1945, el país presentó una iniciativa ante la Organización de las Naciones Unidas (ONU) en la que se proponía la no inclusión de España como miembro de dicho organismo, propuesta que fue aceptada y sancionada en diciembre del año siguiente, aunque su 
vigencia duró sólo diez años. ${ }^{10}$ Pero en septiembre de 1975, el régimen de Franco adoptó algunas medidas de política interior ante las cuales el gobierno mexicano reaccionó, desatándose una crisis que, a pesar de su magnitud y su duración de carácter menor, dejó ver no sólo la nueva orientación de la política exterior de Echeverría, sus alcances y limitaciones, sino además reveló aspectos interesantes de la política y el poder en México.

En efecto, el 26 de agosto de 1975 fue promulgada en España una ley sobre "prevención del terrorismo", según la cual se impondría pena de muerte a las personas involucradas en hechos delictivos en los que resultaran muertos agentes de la autoridad, miembros de las fuerzas armadas o de la seguridad del Estado y/o funcionarios públicos. La pena capital recaería también en quienes organizaran, dirigieran, participaran, aportaran dinero o medios materiales a organizaciones o grupos "comunistas, anarquistas, separatistas" o que "preconizaran o emplearan la violencia" como instrumento de acción política o social. El argumento gubernamental para la promulgación de esa ley, en palabras de un alto funcionario español, era que se trataba de un instrumento jurídico necesario ante la "escalada terrorista", que no suspendía ninguna garantía constitucional y que su objetivo último era una "mejor protección social". ${ }^{11}$ 35-40.

${ }^{10}$ De la Pedraja y Treviño, Méxtco, 1983, pp.

11 España al Día, núm. 47, p. 1. Las declaraciones son del subsecretario de Justicia español.
Amparado en dicha ley, el gobierno franquista condenó a muerte a once jóvenes, detenidos bajo el cargo de terrorismo, por medio de juicios declarados "sumarísimos", los cuales permitían la aceleración de los procedimientos y la disminución de las posi. bilidades de la defensa eliminando la apelación ante el más alto cuerpo juridico, el Tribunal Supremo Militar. Se esperaba que otras condenas llegarian pronto, pues la policía tenía arrestadas, bajo los mismos cargos, a poco más de 50 personas. El 24 de septiem. bre, las Capitanías Generales de Barcelona y Madrid confirmaron seis de las once penas de muerte: una contra el activista vasco Juan Paredes Manot y las otras contra cinco militantes del llamado "Frente Patriótico Revolucionario Antifascista", entre los cuales se encontraban dos muchachas embarazadas. ${ }^{12}$

La decisión de ejecutar a los prisioneros antifranquistas desató una cade. na de reacciones, tanto en España como en el resto del mundo. El príncipe Carlos Hugo de Borbón pidió al general Franco indultara a los condenados y monseñor Narciso Jubany, cardenal arzobispo de Barcelona, solicitó una actitud de "generosidad y magnanimidad" de parte del gobernante. ${ }^{13}$ En Italia, Holanda, Inglaterra, Francia, Suiza y Alemania se produjeron diversas manifestaciones y declaraciones, por parte de grupos, personalidades políticas, eclesiásticas e intelectuales y funcionarios gubernamentales, en las que se repudió la de-

12 El Nacional, del 12 al 21 de septiembre. 13 Ibid., 25 de septiembre, 1975, pp. 2 y 14. 
cisión, se condenó al gobierno fran. quista y se solicitó el indulto. El papa Paulo VI intervino por la vía diplomáti$\mathrm{ca}$, solicitando al generalísimo dispensar la gracia. ${ }^{14}$ Siete personalidades francesas, entre las que se encontraban el actor Yves Montad, el director de cine Costa Gavras, los periodistas Jean Lacouture y Claude Mauriac, y los intelectuales Régis Debray y Michel Foucault, volaron a España para difundir un llamamiento firmado por ellos mismos desde luego, pero además por los escritores André Malraux y Jean Paul Sartre y por el ex jefe de gobierno francés Pierre Mendes France, entre otros, en el cual se apelaba a favor de los condenados. La delegación francesa llegó a Madrid el 22 de septiembre al mediodía, se dirigió al hotel en el que se hospedaría y desde allí ofreció una conferencia de prensa. Durante la conferencia, sin embargo, hizo acto de presencia la policía española y arrestó a los franceses, a los que deportaron el mismo día. ${ }^{15}$

La actitud oficial apuntaba hacia la inflexibilidad. No obstante, la protesta internacional provocó que el gabinete español convocara a reunión para discutir expresamente el asunto de la reacción mundial ante las medidas "antiterroristas". Se suponía que en casos de emergencia, como el que se vivía entonces, el gabinete asesoraba a Franco en su decisión final. El 25 de septiembre tuvo lugar tal reunión, de la que oficialmente no se tuvo conocimiento sobre lo tratado en ella; sin embargo, la prensa local comentó que

14 Ibid., 20 de septiembre, 1975, p. 2.

15 Ibid., 23 de septiembre, 1975, p. 2. se produjo cierta disensión entre los miembros del gabinete a la hora de decidir si se llevaban a cabo o no las ejecuciones, aunque un portavoz oficial negó tal versión. ${ }^{16}$

No obstante el desacuerdo en su gabinete, si lo hubo, y la condena internacional a la pena de muerte, Franco decidió perdonar la vida a seis de los inculpados, entre ellos a las dos jóvenes encinta, pero no en el caso de dos separatistas vascos y de tres extremistas de izquierda. Así, los cinco condenados serían ejecutados el sábado 27 de septiembre, en tres prisiones de Barcelona, Burgos y Madrid, con el cruel método denominado "garrote vil" ${ }^{17}$ Aunque finalmente no se usó tal método, los cinco condenados fueron ejecutados. Las protestas en todo el mundo arreciaron: los gobiernos de Portugal, Francia, Italia, Gran Bretaña, Alemania Oriental y Occidental, Bélgica, Suecia, Noruega, Irlanda, Suiza, Dinamarca y Holanda retiraron provisionalmente sus embajadores en España; se produjeron manifestaciones en varias ciudades de Europa en las que se atacaron oficinas y embajadas espa-

16 Ibid., 26 de septiembre, 1975, p. 2.

17 Ibid., 26 de septiembre, 1975. El "garrote vil" se convirtió, desde el siglo Xvil, en el método para ajusticiar a delincuentes de derecho común. El condenado era sentado con la espalda apoyada contra un poste; acto seguido el verdugo colocaba en su cuello un aro de hierro cerrado por un tornillo. Con una manivela, el verdugo accionaba el tornillo que, al cerrar el collar metálico, estrangulaba lentamente a la víctima hasta quebrarle las vértebras cervicales. El último ajusticiado con el método del garrote vil fue el anarquista catalán Salvador Puig Antich, el 8 de marzo de 1974, quien demoró doce minutos en morir. 
ñolas; hubo declaraciones de distintas personalidades, algunas enérgicas como las de Olof Palme. ${ }^{18}$

En México, la noticia de la condena a los antifranquistas no pareció llamar al principio la atención. El día 4 de septiembre apareció en la prensa un manifiesto firmado por diversas organizaciones de republicanos españoles, en el que se informaba a la opinión pública de la decisión de las cortes marciales, en el que se protestaba por el fallo judicial, por el procedimiento que se consideraba parcial y arbitrario y por la ley antiterrorista, y en el que se convocaba a "los hombres y pueblos libres" a solidarizarse con España y evitar las ejecuciones. Al día siguiente, una organización denominada "Juventudes Mexicanas Pro-derechos Humanos" convocó a un acto de protesta en el parque España de la ciudad de México, con las consignas de detener al "verdugo" y salvar la vida de los prisioneros. ${ }^{19}$ Salvo estas manifestaciones, nadie pareció reparar en lo que pasaba en España. Hasta que apareció Echeverría.

Una vez que se supo que los pelotones de fusilamiento españoles entraron en acción, el primero en reaccionar en México fue el presidente. Dice don Daniel Cosío Villegas que una de las constantes psicológicas de Echeverría era su "incapacidad de reposar, la prisa con que se mueve, la prisa con que quiere hacer las cosas" ${ }^{20}$ Y efectivamente, el presidente se enteró de las ejecuciones en una gira de trabajo en Amecameca y, sin esperar a nada ni

18 Excélstor, 29 de septiembre, 1975, p. 3.

19 rbid., 4 y 5 de sept., 1975, pp. 12-A y 2-A.

${ }^{20}$ Cosío Villegas, Estilo, 1974, p. 40. a nadie, preparó un mensaje dirigido al secretario general de la ONU, Kurt Waldheim, que hizo leer alli mismo por su director de prensa y relaciones públicas. Fue el inicio de las discordias hispano-mexicanas de 1975.

\section{LAS DISCORDIAS HISPANO-MEXICANAS}

La nota que envió Echeverría a Waldheim sorprendió a propios y extraños. En ella solicitó al secretario general que convocara con "carácter de urgente" a una reunión extraordinaria del Consejo de Seguridad, para que éste a su vez, de conformidad con los artículos $5^{\circ}$ y $6^{\circ}$ de la Carta Constitutiva de las Naciones Unidas, pidiera a la Asamblea General que el régimen español fuese suspendido del ejercicio de los derechos y privilegios inherentes a su calidad de miembro. Solicitó, además, que intercediera para que el mismo Consejo, con base en el artículo 41 , instara a los miembros de la ONU a interrumpir "totalmente" sus relaciones económicas y diplomáticas con España, así como las comunicaciones ferroviarias, marítimas, aéreas, postales, telegráficas, radioeléctricas y "otros medios de comunicación".21

Echeverría fundamentaba su solicitud no sólo en los artículos citados, sino en consideraciones de orden político y moral. Así, argumentaba en su nota que México unía "su convicción y su voz" de manera "vehemente" a la de la comunidad internacional que condenaba "las graves y repetidas vio-

21 El Nacional, 29 de septiembre, 1975, p. 1. 
laciones a los derechos humanos" que cometía el régimen "dictatorial" de Franco, el cual ofendía al pueblo español. Aunque México, afirmaba el presidente, había sido siempre un defensor de los principios de autodeterminación y no intervención en los asuntos internos de los Estados, en esta ocasión no quería ser cómplice de los actos "contrarios al pacto jurídico" en que se fundaba la existencia de las Naciones Unidas, en que incurría la "conducta criminal" de la "dictadura que agobia a España". Por tal razón, y porque la dictadura española fue impuesta por el "nazifascismo", era hora de que todos los países que habían mantenido hasta entonces relaciones con España cambiaran su actitud e hiciesen "una honrada rectificación a su conducta". Pero había más: según el presidente mexicano, las consecuencias internas de la dictadura franquista, "como ocurre en otros países y en otras regiones del mundo", provocarían "la intervención y la confrontación, abierta o disimulada, de las grandes potencias" y ello pondría en peligro la paz mundial. ${ }^{22}$

La nota desató una controversia de índole jurídica, política, diplomática y moral, en la que se vieron involucrados no sólo los gobiernos mexicano y español, sino también grupos y personalidades de ambos países así como de otras naciones $\mathrm{y}$, desde luego, las $\mathrm{Na}$ ciones Unidas. En este organismo se enfrentaron las representaciones de España y México. El mismo día en que el presidente Echeverría dio a conocer públicamente su mensaje al secre-

22 Ibid. tario general de la ONU, la representación permanente en Nueva York lo transmitió a Waldheim. España reaccionó rápidamente y un día después, el 29 de septiembre, su representación envió al mismo secretario una carta en la que señalaba que la enviada por México constituía una flagrante violación al artículo 2 , parágrafo 7 , de la Carta de las Naciones Unidas, dado que significaba un intento de intervención en asuntos que eran esencialmente de jurisdicción doméstica. España, además, soltó el primer golpe político: no sólo violaba Echeverría con su nota el principio de no intervención, sino que carecía de la "necesaria estatura moral" para acusar a cualquier gobierno, puesto que había participado como funcionario gubernamental de primer nivel en los acontecimientos de Tlatelolco en 1968. La disputa diplomática continuó en el seno de la onu. México respondió diciendo que España desviaba, con acusaciones de índole personal dirigidas a Echeverría, el asunto fundamental: las violaciones a los derechos humanos cometidos por el gobierno franquista, que la propia comunidad internacional había ya condenado; España insistió en que el tono y el contenido de las notas mexicanas constituían una interferencia en asuntos de estricto orden interno. Un pequeño impasse se produjo en el organismo cuando, el 3 de octubre, el presidente del Consejo de Seguridad dirigió al secretario general un oficio en el que le informaba que, una vez realizadas las consultas de rigor, se había llegado al consenso de que, sin juzgar el contenido de la petición mexicana, el Consejo no 


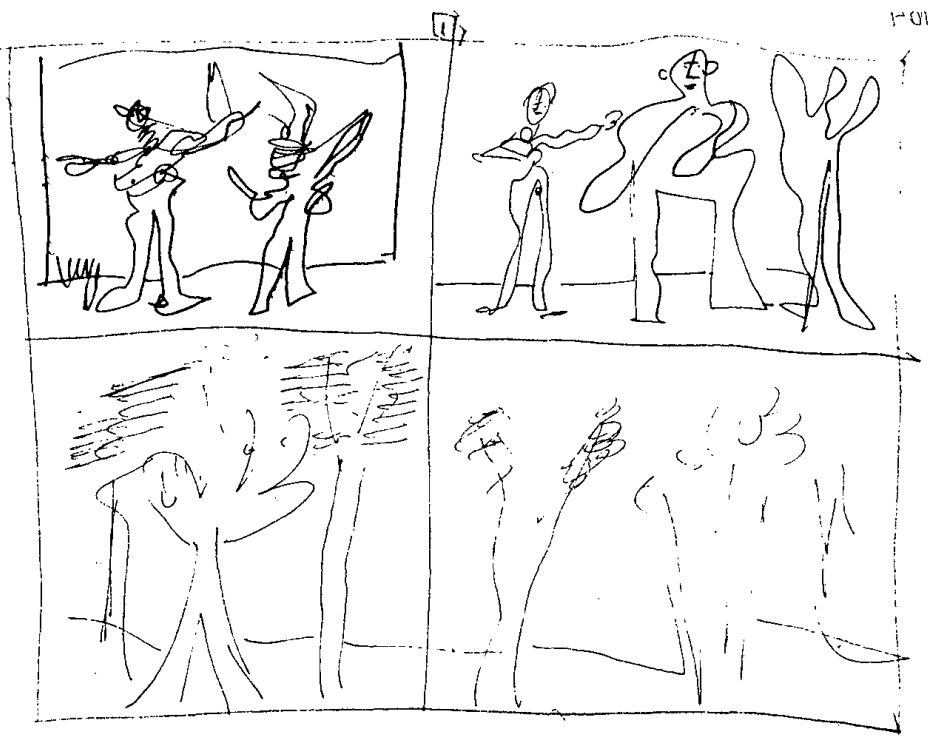

era el foro adecuado para tratar el tema. ${ }^{23}$

El Consejo de Seguridad encontró la forma jurídica para no involucrarse en la discusión sobre la petición mexicana, pero ello no significó que el conflicto hubiese terminado; sólo se desplazó de escenario. En efecto, en diversos círculos políticos y sociales de España y México las disputas continuaron. El periódico $A B C$ comentó, el día 30 de septiembre, que la decisión del Consejo de Seguridad de no reunirse para discutir la petición mexicana

23 Véase la disputa diplomática en United Nations, Yearbook, 1978, pp. 319-321. Las notas de las representaciones española y mexicana pueden consultarse, respectivamente, en $A B C$, 30 de septiembre de 1975, y en Díaz y Martini, Relaciones, 1977, p. 372. era "bastante indicativa" de lo "poco apropiado" que había sido considerada y de la "deliberada exageración que revestía sus términos". ${ }^{24}$

Por su parte, Echeverría decidió, el mismo día de su comunicado a Waldheim, suspender todo tipo de relaciones y comunicaciones que, en los hechos, se sostenían con España. A partir del 29 de septiembre, en consecuencia, la línea aérea Aeroméxico dejó de prestar sus servicios para vuelos cuyo destino fuese España; la Secretaría de Gobernación, a su vez, notificó al representante oficioso del gobierno español y al corresponsal de la agencia española de información EFE que debían de cerrar inmediata-

${ }^{24} A B C, 30$ de septiembre, 1975. 
mente sus oficinas y abandonar el país en un lapso de $\mathbf{4 8}$ horas; la Secretaría de Turismo informó al encargado de las oficinas de Turismo de España que debía también salir de país, al igual que se solicitó a la compañía de aviación Iberia cerrara sus oficinas; la Secretaría de Relaciones Exteriores giró instrucciones al embajador en Portugal para que cerrara la sección B del consulado de México en Lisboa que funcionaba en Madrid, así como también todas y cada una de las oficinas de los distintos organismos mexicanos establecidas en España, como el Consejo Nacional de Turismo, el Instituto Mexicano de Comercio Exterior, el Banco Nacional de Comercio Exterior, Películas Mexicanas, el Fondo de Cultura Económica y otras más de índole comercial. El oficial Canal 13 de televisión, por su parte, anunció que solicitaría la exclusión de la dependencia gubernamental "Radio y Televisión Española" de la Organización de la Televisión Iberoamericana, en tanto no se produjera un cambio en el "régimen dictatorial" que oprimía al pueblo español; mientras tanto decidió excluir de la programación del canal todos los programas españoles, incluyendo películas y cualquier evento deportivo que tuviese lugar en la "España fascista". ${ }^{25}$

Las medidas que tomó el gobierno mexicano encontraron apoyo en el mundo político oficial y tuvieron eco en algunos sectores sociales. José López Portillo, ya candidato del Partido Revolucionario Institucional (PRI) a la

25 El Nacional, 29 de septiembre y 2 de octubre, 1975, p. 1 y p. 20. presidencia de la república, calificó de "vileza" las ejecuciones franquistas y expresó que estaba con el presidente Echeverría. Porfirio Muñoz Ledo, presidente del Comité Ejecutivo Nacional del PRI, señaló que la actitud del presidente ante la España franquista era una comprobación de que el "régimen de la revolución" siempre había tenido razón y que afirmaba la "dignidad" de la política exterior mexicana; pidió además a los legisladores prístas que realizaran un acto de "plena solidaridad" con la decisión gubernamental. Echeverría recibió apoyos también de Fidel Velázquez, la Confederación Campesina Independiente, la Cámara Nacional de la Industria de la Transformación, la Confederación Nacional Campesina, la Confederación Nacional de Organizaciones Populares, del Congreso de la Unión, de los dirigentes del Partido Popular Socialista y del Partido Auténtico de la Revolución Mexicana $y$, por supuesto, de los republicanos españoles exiliados en México. ${ }^{26}$

Los editoriales de la prensa fueron, por lo general, positivos. El periódico El Nacional, por obvias razones, fue el más vehemente defensor del presidente. Las páginas editoriales de los días 30 de septiembre y 1 de octubre estuvieron dedicadas, casi íntegramente, a apoyar las medidas gubernamentales contra el gobierno español. En ellas es posible encontrar expresiones del tenor siguiente: la decisión de Echeverría formaba parte de una misma actitud asumida desde 1936, que encontraba fundamento en la "obra

${ }^{26}$ Ibid, 29 y 30 de septiembre y 1 de octubre, 1975; Excélstor, 29 de septiembre, 1975. 
del fascismo en España" y en el "ser histórico" de México; las medidas, lejos de adoptar un "proceder inamistoso" para con el pueblo español, actuaban en favor de él y expresaban un "criterio nacional" del cual Echeverría era un "fidelísimo ejecutor"; las disposiciones del presidente eran la única reacción posible ante la "barbarie fascista" cuyas ejecuciones tenían un "perverso significado"; así como el México de Cárdenas escribió un "capítulo hispánico en la guerra española de 1936", el México de Echeverría escribió un "noble infolio" en la guerra presente; Echeverría, haciendo honor a la "herencia" de Cárdenas, no se quedaba sólo en el terreno de las "protes. tas y lamentaciones verbales"; era un "inepto razonamiento" el decir que la solicitud del presidente a la ONU significaba una intromisión en los asuntos internos de España. ${ }^{27}$

Luis Quintanilla, representante de México ante la oNU en 1945, argumentó que la posición de Echeverría estaba apegada al derecho internacional y que, además, se correspondía con la tradición internacionalista de México, pues desde 1945 se había presentado la iniciativa de que España no perteneciera a la ONU, iniciativa que le había correspondido presentar. Treinta años después la historia se repetía para el doctor Quintanilla y el presidente era congruente con la conducta internacional de México: "por su boca" hablaba "indiscutiblemente" la "voz tradicional de México". ${ }^{28}$

${ }^{27}$ El Nacional, 30 de septiembre y 1 de octubre, 1975.

${ }^{28}$ Entrevista concedida a El Nacional, 2 de octubre, 1975, p. 10.
Se presentaron, porotro lado, manifestaciones antifranquistas de algunos grupos mexicanos. La prensa reportó que "grupos de jóvenes simpatizantes con el movimiento separatista vasco" habían prendido fuego a las oficinas de la representación oficiosa del gobierno español y apedreado las oficinas españolas de turismo y de la compañía de aviación Iberia. La policía, se informó, recogió en los lugares del atentado volantes alusivos al movimiento separatista vasco y otros en los que se condenaba a Franco y los fusilamientos de los cinco jóvenes vascos. Días después, se organizó una manifestación en la que participaron "miles de personas", se condenó el régimen franquista y se quemó una efigie de Franco. El acto terminó con consignas co. mo la de "garrote vil para Franco" y con un minuto de silencio en memoria de las víctimas del "fascismo español". 29

El gobierno franquista reaccionó ante los ataques. En la ONU intentó obstaculizar las gestiones mexicanas y, de paso, descalificar al gobierno de México y a su presidente. El embajador español ante el organismo internacional, Jaime de Piniés, calificó de inaceptable la solicitud de Echeverría por violatoria del principio de no intervención, a más de haber sido escrita según él en un lenguaje "nunca antes usado en el Consejo de Seguridad". Piniés fue más allá y declaró en Nueva York, ante la prensa, que su país jamás solicitó la intervención del Consejo cuando se supo de la "matanza de

${ }^{29}$ Excélsior, 29 de septiembre y 4 de octubre, 1975, pp. 1 y 2.

MARCO ANTONIO LANDAVAzO ARIAS 
cientos de estudiantes mexicanos en 1968 , época en que Echeverría era ministro del interior"; por si fuera poco, el embajador refírió que en un libro escrito por Philippe Agee, el presidente mexicano aparecía como "estrecho colaborador" de la Agencia Central de Inteligencia de los Estados Unidos, en donde actuaba bajo el nombre clave de "Litempo-14". No obstante, aseguró que no le sorprendía la "intolerable intervención" de Echeverría en los asuntos internos de España, pues no era la primera vez que eso sucedia. Sobre las relaciones entre México y el gobierno republicano en el exilio, en un tono evidentemente irónico, señaló que se trataba de relaciones con un gobierno que, desde hacía 31 años, no existía. En la nota que De Piniés envió a Waldheim después de formular las declaraciones anteriores, el embajador repitió los mismos argumentos y críticas al presidente mexicano, pero añadió otros: Echeverría había cometido un "crimen deliberado" en la cárcel de Lecumberri, en 1972, cuando varios presos políticos fueron asesinados por reclusos del orden común, presuntamente instigados por las autoridades. ${ }^{30}$

El gobierno central en Madrid, por su parte, hizo lo suyo. El día 29 de septiembre declaró que rechazaba "con toda energía" las protestas internacionales por las ejecuciones y enfatizó que de ningún modo se dejarían intimidar. La televisión española difundió ese mismo día un mensaje del primer ministro Carlos Arias Navarro

${ }^{30} A B C, 30$ de septiembre, 1975 y Excélsior, 30 de septiembre, 1975, p. 1. sobre la petición mexicana ante la oNU y sobre la intención del gobierno mexicano, calificándolas a la primera de "pintoresca" y a la segunda de "cínica", con el mismo argumento de la participación de Echeverría en los sucesos de 1968. Esa acción sí fue violatoria de los derechos humanos, agregó Arias Navarro, pues los centenares de estudiantes muertos lo fueron "gratuitamente" y "el juicio, veredicto y ejecución" de las víctimas fueron "simultáneos: las ametralladoras". La crítica no se detuvo allí y tocó al régimen de gobierno mexicano: éste, según el primer ministro, se regía por un sistema de partido "tan mayoritario" que en la práctica había resultado de "partido único"; además había dado "a la ciencia política figuras tan sui generis como el tapado", gracias a lo cual los mexicanos sabían, "sin posibilidades de error", quién llegaría a ser su próximo presidente: naturalmente el que fuese apoyado por el "partido único". 31

En posteriores mensajes, el gobierno declaró que no cejaría en su empeño de "erradicar" el terrorismo y que, por ello, continuaría aplicando la pena de muerte a quienes participaran en "delitos políticos". También se pidió calma ante las crecientes protestas internacionales y se llamó al pueblo español a "continuar trabajando fervientemente por la paz nacional" y a mostrar a Francisco Franco "testimonio de inolvidable gratitud y respeto por su obra". Los ataques que sufría el régimen franquista y su identificación como ataques a la nación, promovida

31 Ibid., 30 de septiembre, 1975, p. 1. 
por los llamamientos oficiales, provocaron la movilización de importantes contingentes en apoyo a España y, al final de cuentas, al gobierno de Franco. En Córdoba y Huelva se manifestaron alrededor de 125000 personas contra las condenas del exterior y más de 150000 se congregaron en la Plaza de Oriente de Madrid, en donde aclamaron al generalísimo, quien estuvo presente en el acto por espacio de tres minutos y en donde expresó a la multitud que España era atacada por una "conspiración masónica izquierdista" y que era víctima de la política de "ciertos países corruptos". ${ }^{32}$ No fue sorpresa, así, que algunos grupos de jóvenes apedrearan las oficinas en Madrid de la compañía aérea Aeroméxico y destruyeran su mobiliario. ${ }^{33}$

El gobierno español fue más allá de las declaraciones y adoptó también algunas medidas contra México. Decidió, por ejemplo, expulsar a los funcionarios y turistas mexicanos que se encontraran en territorio español, mientras que el Banco de España suspendió la cotización del peso mexicano, por lo que dicha moneda no podría cambiarse. Artistas y toreros que se encontraban en esos momentos en España tuvieron que abandonar de igual forma el país. Hasta el catalán Juan Manuel Serrat se hizo acreedor a una sanción, pues la Junta Nacional del Sindicato Español de Artistas acordó expulsarlo de sus filas y suspender el visto bueno en los contratos que presentase, ya que durante su estancia

32 El Nactonal, 1 y 4 de octubre, 1975, pp. 4 y 2; Time, 13 de octubre, 1975, pp. 8-16.

33 El Nacional, 2 de octubre, 1975, p. 10. en México declaró que siempre había condenado la represión del gobierno franquista y que, por ello, aplaudía la decisión del presidente Echeverría de romper toda relación con España. ${ }^{34}$

En México, el periódico España al Día, editado por españoles, sin entrar en conflicto con el gobierno mexica. no obviamente criticó sin embargo las protestas contra España y defendió las ejecuciones de los antifranquistas. En el editorial de su número 49 , la publicación señalaba particularmente a Francia e Inglaterra como los países que más criticaban a su país por haber ejecutado a terroristas, cuando en esos países las medidas antiterroristas eran tanto o más enérgicas que en España. ${ }^{35}$

Voces críticas de las decisiones de Echeverría se escucharon también en México. Ciertamente el apoyo y defensa fueron mayores y provinieron no sólo de plumas oficiales sino también de comentaristas independientes, como Gastón García Cantú, quien consideró que la cancelación de toda relación con España había sido una rectificación, pues aunque se mantenían rotas las relaciones diplomáticas, desde 1945 se sostenían vínculos de tipo comercial, cultural y humano. La medida del presidente, para García Cantú, recuperaba una "tradición casi olvidada". 36

Pero otros emitieron opiniones distintas. Javier Peñalosa, Pedro Gringoire y José Fuentes Mares en Excélsior, Alberto Domingo en la revista Siem-

${ }^{34}$ Ibid., 2 y 16 de octubre, 1975, pp. 10 y 20.

35 España al Día, núm. 49, 29 de septiembre, 1975, p. 3.

${ }^{36}$ Excélsior, 3 de octubre, 1975, p. 27. 
pre y el Partido Acción Nacional (PAN), fueron los principales críticos de la decisión de romper las relaciones de facto con España. El principal cuestionamiento fue que la medida pecaba de inmadurez e imprudencia y que atentaba contra el pueblo español, más que contra el gobierno, y por ello resultaba arbitraria y violatoria de derechos humanos fundamentales como el de libre tránsito.

El historiador Fuentes Mares señaló, por ejemplo, que la decisión de que ningún consulado mexicano extendiera visas de turista a ciudadanos españoles contradecía el dicho del presidente según el cual repudiaba al gobierno de España mas no a su pueblo. Javier Peñalosa sostuvo una postura similar, pues expresó que la medida era señal de inmadurez y que estaba dirigida contra el pueblo español, más que contra su gobierno. Gringoire, por su parte, escribió que era "entendible" la energía con la que procedía el presidente, pero agregaba que no de. bían sufrir los españoles el castigo que se quería aplicar al dictador. ${ }^{37}$

El Partido Acción Nacional fue el único partido político legal que no se sumó a las aclamaciones de las medidas gubernamentales. Sin justificar los fusilamientos o el régimen español, el PAN declaró que rechazaba "la hipocresía de quienes, sin distinguirse precisamente por su respeto efectivo a la Carta de la ONU", miraban la "paja en el ojo de Franco" y no veían "la viga en los propios" y agregó que bastarían "dos hechos, Tlatelolco y Jueves de Corpus", para que México mereciera

${ }^{37}$ Ibid., 2 y 4 de octubre, 1975, editorial. la suspensión en la ONU. Igual suerte podrían correr otros países - señaló el PAN - que violaban sistemáticamente derechos humanos, como Cuba, China, Rusia, Alemania Oriental, Haití, Perú y Brasil, de aplicarse con rigor los artículos de la Carta. Por lo demás, para el partido derechista el gobierno español, fuese cual fuese la opinión que de él se tuviese, "actuó conforme a sus propias leyes al ejecutar a cinco terroristas condenados a muerte". 38

Quizás la crítica más incisiva fue la de Alberto Domingo. El articulista de Siempre empezó su escrito señalando que no se trataba de estar con Franco sino de "no estar contra España". Apuntó que Franco era el mismo represor de hacía treinta años y que México tampoco había cambiado, pero ahora el país se había dejado "desbordar por el encono". De tiempo atrás, aun contra Franco, México había tendido puentes de convivencia e intercambio comercial y cultural y no había motivos válidos para el articulista que llevasen a dejar de respetar las "relaciones humanas". Agregaba que asesinatos, disturbios y represiones ocurridos en los últimos años en México, comentados en la prensa mundial con tonos "rabiosos", no produjeron sin embargo que les cerrasen la puerta a los mexicanos en ninguna parte del mundo; pero además la eficacia de la medida era dudosa: ¿acaso habría de caer Franco prohibiendo a mexicanos y españoles el derecho de viajar y comunicarse? Era de justicia apoyar al pueblo español, pero no aislándolo ni bloqueándolo, en un "exceso de vehemencia".

38 Ibid., 30 de septiembre, 1975, p. 10. 


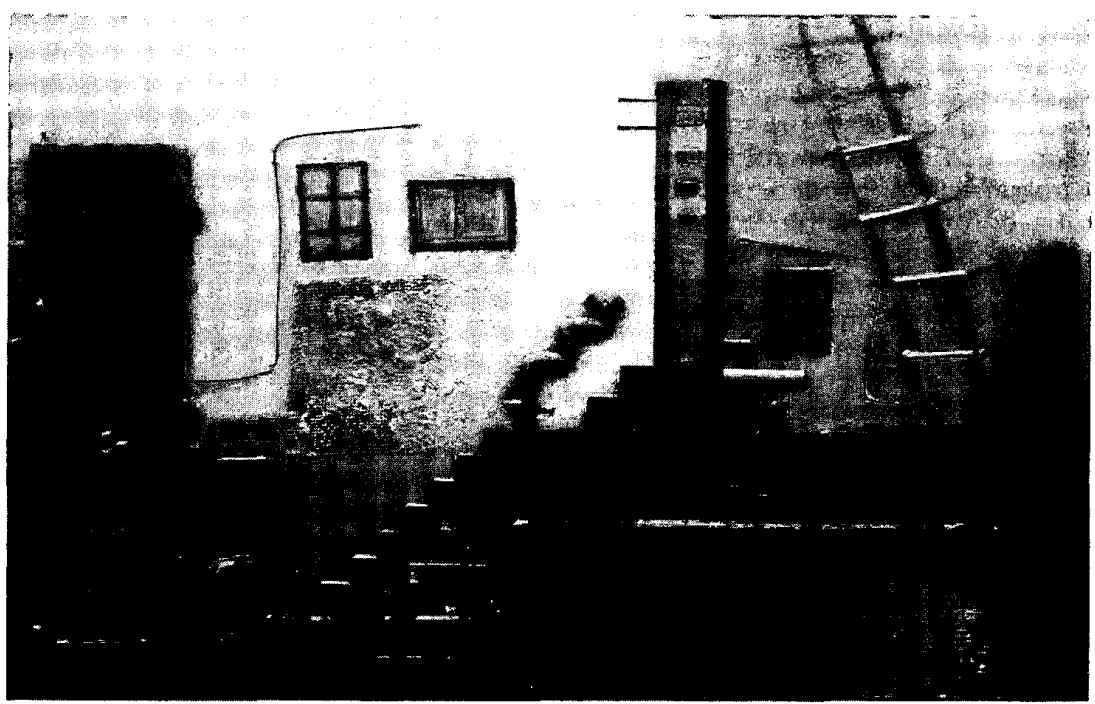

Terminaba Domingo afirmando que la "prudencia y la sensatez" no eran incompatibles con "la verticalidad ante cualquier régimen de reprobable fuer. za". 39

El presidente Echeverría, no obstante, persistió en sus empeños. Había recibido el apoyo no sólo de personalidades y grupos mexicanos, sino también de otras latitudes. El gobierno republicano en el exilio, con sede en París, le hizo llegar el día 1 de octubre un mensaje de gratitud por las medidas adoptadas contra el régimen franquista, firmado por su presidente José Maldonado y por el jefe de gobierno Fernando Varela. ${ }^{40}$ Por otra parte, cua-

${ }^{39}$ Siempre, 12 de octubre, 1975, p. 15.

${ }^{40}$ El Nacional, 2 de octubre, 1975, p. 10. tro embajadores que se acreditaron ante el gobierno mexicano declararon que la situación en España era "seria y muy grave" y dos de ellos, los representantes de Polonia y Hungría, consideraron que aislar totalmente a España era la contribución "más concreta" a la causa del pueblo español y "de la paz del mundo". El nuevo embajador de Hungría, incluso, señaló que su país apoyaría la iniciativa de México para que España fuera expulsada de la ONU. 41

Así, Echeverría decidió reiterar su petición a la ONU en la propia sede del organismo, pues con antelación se había programado su participación, el día 7 de octubre, en la sesión ordinaria

41 Ibid., 3 de octubre, 1975, p. 9. 
número 30 de la Asamblea General que tendría lugar ese día. Previamente, el Centro Republicano Español había informado en conferencia de prensa que una delegación española, encabezada por el presidente del Consejo de Ministros del gobierno republicano en el exilio, Francisco Urea, se encontraba en Nueva York para apoyar al presidente Echeverría en su comparecencia. ${ }^{42}$ Llegado el momento de su intervención, el mandatario mexicano abordó diversos temas: los problemas de la paz, los precios del petróleo, el sistema económico para el tercer mundo, el armamentismo y la situación del Medio Oriente. Casi para finalizar tocó el tema español. Expresó:

En relación con los sucesos acaecidos en España ratifico, con firmeza y serenidad, la petición mexicana elevada a la consideración del Consejo de Seguridad el día 28 de septiembre próximo pasado, consciente de que técnica y políticamente nos asiste la razón. Técnicamente, porque esta petición se ajusta a los términos de la Carta de las Naciones Unidas, que confiere a cualquier Estado miembro el derecho de denunciar ante el Consejo de Seguridad este tipo de situaciones; políticamente porque los hechos de que nos ocupamos no sólo constituyen una reiterada violación de los derechos humanos, se trata, ante todo, de la creación sistemática de un clima de confrontación violenta susceptible de conducir a una fricción internacional y poner en peligro el mantenimiento de la paz en un punto de la tierra que, por ser de interés estratégico, amenaza la seguridad mun. dial. Así lo demuestra la magnitud de la

${ }^{42}$ Ibid., 7 de octubre, 1975, p. 6. protesta mundial, que en este caso ha suscitado. Así lo demostrará, irremediablemente, la historia. ${ }^{43}$

Las crónicas de la prensa reportaron que, al terminar su discurso, una gran mayoría de delegados aplaudió al presidente mexicano y que unos 50 españoles antifranquistas "estallaron en un fuerte aplauso". Más tarde, el embajador español Jaime de Piniés intentó usar el derecho de réplica después del discurso de Echeverría, pero el presidente de la Asamblea, Gastón E. Thorn, le pidió abandonar ese derecho "por cortesía", argumentando que su aplicación en el caso de jefes de Estado "desanimaría a éstos a hablar ante la Asamblea". 44

No obstante, el embajador De Piniés respondió por escrito al mensaje de Echeverría, en una carta enviada a Waldheim que después fue distribuida como documento de la Asamblea General. En su carta, De Piniés señaló que no podía dejar pasar en silencio "el nuevo intento del presidente de México de intervenir en los asuntos internos de España" en su alocución a la Asamblea, denunciándolo como "contrario a los principios y a las resoluciones de las Naciones Unidas". Utilizando los mismos términos que usó Echeverría, el embajador español expresó que su gobierno rechazaba la imputación mexicana según la cual el

43 "Discurso del presidente Luis Echeverría Älvarez en el XXX periodo ordinario de sesiones de la Asamblea General de la ONU", en Centro Republicano Español de México, 1978, pp. 425. 430. También en El Nactonal, 8 de octubre, 1975, p. 8.

${ }^{44}$ El Nacional, 8 de octubre, 1975, p. 1. 
gobierno español era el causante de una situación que ponía en peligro la paz mundial, por ser "políticamente injustificable" y "técnica y legalmente contraria a la Carta constitutiva y a la doctrina consagrada por las resoluciones de las Naciones Unidas". Agregó que el intervencionismo mexicano databa de 1939, cuando el gobierno de México rompió relaciones con España y, después, en 1945, cuando participó en la administración de "los bienes españoles de propiedad de particulares y que, producto del expolio", habían llegado a México en el yate "Vita".45

El presidente Echeverría continuó en México, sin embargo, con actos y declaraciones antifranquistas. El día 22 de octubre asistió a un desayuno que, en su honor y como muestra de agradecimiento por su posición ante España reiterada en la ONU, organizaron los republicanos españoles en México. Allí pronunció un discurso en el que afirmó que la actitud asumida frente al gobierno de Franco no era "quijotesca", pues se defendía al mismo tiempo "la honra y la hacienda, los intereses morales, espirituales y económicos, del presente y del futuro"; era, más bien, una actitud "práctica, de una utilidad trascendente" que debería "prever casos semejantes en nuestro país". Esto era así, porque la situación de España, de México y "de todo el tercer mundo" admitía "una explicación global": detrás de todos estos problemas está la política de

45 "Carta de Jaime de Piniés a Kurt Waldheim", Revista de Política Internacional, núm. 142, nov.-dic., 1975, pp. 229-231. "equilibrio y componendas" de las grandes potencias; si éstas buscan verdaderamente la paz, "deberían de adoptar las medidas y tomar las decisiones que México ha solicitado y en las cuales ha insistido". 46

El mismo día en que Echeverría pronunció ese discurso, en España el generalísimo Franco sufrió un ataque al corazón, el tercero en el curso de cinco días. Una semana atrás había caído enfermo de gripe y el día 18 de octubre un boletín médico oficial anunciaba que sufría complicaciones cardiacas. El priner ataque, que fue descrito como severo, tuvo lugar el día siguiente, martes, y el segundo, el día jueves. ${ }^{47} \mathrm{La}$ salud del gobernante fue empeorando hasta tal punto, que el rey Juan Carlos tuvo que asumir la jefatura del Estado el día 30 de octubre, ante el vacío de poder que se produjo por la virtual ausencia de Franco y la grave situación política que vivía España, sobre todo por el conflicto derivado del proceso de descolonización del Sahara. 48

Franco murió el día 20 de noviembre y las expectativas de que el conflicto con México terminara, aumentaron. El presidente mexicano había declarado, es cierto, que no habrían de restablecerse relaciones con España si el franquismo se entronizaba en ese país, aun cuando Franco desapareciera. Tal vez por ello los vínculos

46 "Discurso de Luis Echeverría Álvarez ante republicanos españoles en México" ${ }^{n}, 23$ de octubre de 1975, en Centro Republicano Español de México, 1975, pp. 56.64.

${ }^{47}$ El Nactonal, 23 de octubre, 1975, p. 2. 1975.

${ }^{48}$ Excélsior y El Nacional, 31 de octubre, 
diplomáticos se establecieron hasta el 28 de marzo de 1977, con José López Portillo como presidente de la república. Al parecer, fue necesario que también desapareciera Echeverría, así sea políticamente, para que pudiera concretarse esa reanudación, pues según la prensa existían en medios oficiales de Madrid, "fuertes resistencias" a cualquier comunicación tendiente a un restablecimiento de las relaciones entre ambos países, pues si Echeverría había roto "de forma violenta e inadmisible" los vínculos comerciales, no interesaban entonces los de carácter diplomático. ${ }^{49}$

No obstante, la desaparición del caudillo aligeró las tensiones entre España y México, iniciadas el 28 de septiembre de 1975 . El conflicto derivado de la reacción mexicana ante las ejecuciones de los prisioneros terroristas realizadas por el gobierno franquista terminó, propiamente, con la muerte de Franco. Otro tipo de conflictos surgirian a partir de entonces, más estrechamente relacionados con los procedimientos y acuerdos políticos tendientes a la reanudación de re. laciones diplomáticas. Pero resulta sig. nificativo reparar en el hecho de que ello no pudo llevarse a cabo sino hasta que el gobierno de Echeverría llegó a su fin.

\section{CONSIDERACIONES FINALES}

Aunque de corta duración y de bajo perfil, el diferendo entre México y 89-99.

49 De la Pedraja y Treviño, México, 1983, pp.

LA CRISIS ENTRE MÉxICO Y ESPAÑA
España de septiembre de 1975 tuvo repercusiones de importancia y mostró aspectos de interés, por lo que respecta a la política exterior de México y aun de la interior. Una evaluación correcta de los factores que intervinieron en ese episodio puede ayudarnos a desentrañar los significados del mismo y las dimensiones en él presentes. Señalamos con anterioridad que las motivaciones fueron básicamente de tres tipos: exógenas, endógenas y psicológicas. Conviene revisar, entonces, cuáles fueron esos factores y qué peso específico tuvieron.

La postura que asumió en septiembre de 1975 el presidente Echeverría ante los acontecimientos españoles encontraba ciertamente continuidades con una política exterior tradicional, en términos genéricos y en particular hacia España. Sus apologistas lo señalaron con claridad: no solamente era costumbre que el país defendiera los principios básicos de no intervención y autodeterminación, sino que en el caso español se había sido particular. mente crítico con el franquismo y solidario con la república desde 1936. 39; además, en 1945 la representación mexicana en la ONU -como recordó el doctor Luis Quintanilla - había propuesto la exclusión en ese organismo de la España de Franco. Estas actitudes se mantuvieron esencialmente inalterables hasta los gobiernos de Gustavo Díaz Ordaz y de Luis Echeverría Álvarez.

Pero los primeros problemas surgieron con la solicitud misma ante la ONU, pues fue calificada por España como una intromisión en asuntos de orden interno, es decir, como una 
actitud que contrariaba el espíritu de la política exterior tradicional mexicana. Obviamente, el gobierno de México y sus defensores argumentaron que no era ése el caso, pero en las mismas declaraciones oficiales puede percibirse un tono vacilante al respecto. Véase si no el siguiente párrafo de la solicitud que Echeverría hizo a Waldheim:

México ha sido siempre defensor de los principios de autodeterminación y no intervención en los asuntos internos de los Estados, pero ante la reiterada conducta criminal de la dictadura que agobia a España, ahora, como siempre, no quiere ser cómplice de actos contradictorios al pacto jurídico en que se funda la existencia de las Naciones Unidas.

El uso de la conjunción "pero" después de la coma que separa la primera oración, cuya función es expresaroposición o contrariedad, parece revelar una justificación injustificable. El párrafo, así, parece decir: aunque México "ha sido siempre defensor" de ciertos principios, ahora habrá de obviarlos puesto que se presenta una cierta circunstancia (la "reiterada conducta criminal" del gobierno franquista).

Es cierto que la solicitud fue hecha esgrimiendo tres artículos de la Carta Constitutiva de la ONU, el $5^{\circ}$, el $6^{\circ}$, y 41. Mas también la delegación española refirió el artículo $2^{\circ}$ de la Carta para su defensa. Y ambas posiciones encontraron defensores aunque parece ser que la posición mexicana era más débil política y jurídicamente, habida cuenta que era dificil que se considerara que las ejecuciones franquistas, por más repulsivas que fueran, signifi- caran una amenaza para la paz mundial. Pero más allá de la legalidad de las posturas o de los lapsus político-gramaticales, la correlación de fuerzas en el orden internacional fue lo determinante en el curso que siguió la petición mexicana. En efecto, el Consejo de Seguridad se consideró incompetente para conocer de la materia contenida en el escrito de Echeverría y ello significó, casi, que el asunto quedara archivado en la ONU. No podía ser de otra manera si Estados Unidos, miembro principalísimo del Consejo, se encontraba en esos momentos negociando la continuación del convenio militar que tenía con España, el cual amparaba el establecimiento de cuatro bases militares estadunidenses en territorio español. El portavoz del Departamento de Estado norteamericano, Robert Anderson, declaró que las bases militares de su país situadas en Tarragona, Zaragoza y Rota eran "esenciales para la seguridad nacional de Estados Unidos"..$^{50}$ No fue sorpresa así que Estados Unidos, ante el conflicto hispano-mexicano, declarara que irespetaba el principio de no intervención en los asuntos internos de los Estados!

Hubo, tal vez, un error de cálculo político. La cancillería mexicana pensó que había condiciones para que prosperara la petición en la ONU. El presidente del Consejo de Seguridad era en ese momento Moulaye El Hassen, delegado de Mauritania, es decir, el delegado de un país tercermundista y, por ello, se pensó, aliado de México; además, España enfrentaba el

${ }^{50}$ Excélsior, 29 de septiembre, 1975, p. 1. 


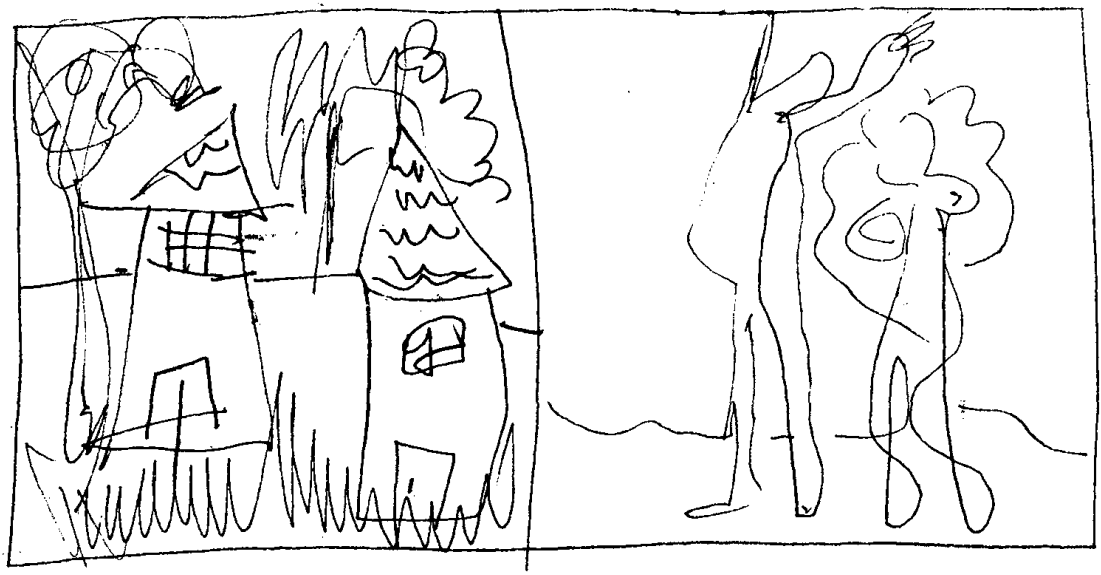

problema del Sahara, que ocasionaba fricciones con los países africanos. Por otro lado, se había presenciado una reacción internacional en contra del gobierno de Franco a raíz de las ejecuciones, que llevaron a varios países de Europa a "llamar a consultas" a sus embajadores ante aquel gobierno; Inglaterra y Francia habían sido dos de los países más críticos de los fusilamientos y, como se sabe, formaban parte del Consejo de Seguridad. Por lo demás, China y la Unión Soviética, ideológicamente enemigos del franquismo, eran también miembros del Consejo. Además, antes de la visita de Echeverría a la ONU, la prensa comentó que el presidente mexicano sería objeto de una "extraordinaria" bienvenida por parte del bloque de países del tercer mundo. Los representantes permanentes de Venezuela, Egipto y Líbano, los que encabezaban los grupos latinoamericano, africano y asiático respectivamente, solicitaron que se verificara una sesión especial del grupo de los 77 para recibirlo, lo que dio lugar a que se especulara que los países tercermundistas apoyarían a México en el asunto español. ${ }^{51}$ Tan convencido estaba el presidente mexicano de las posibilidades de éxito de su solicitud a la $O N U$, que en un discurso que pronunció en Los Pinos ante republicanos españoles que lo visitaron para manifestarle apoyo declaró que el propósito de la solicitud era la de aislar a España para que esto contri-

51 Ibid., 30 de septiembre, 1975, p. 1. 
buyese "a precipitar la caída de Franco". 52 Un despropósito, más bien.

Pero la realpolitik se impuso. Los embajadores inglés y francés (en realidad, todos los embajadores europeos que se había retirado lo hicieron) regresaron pronto a España, y China y la Unión Soviética no secundaron a México. El delegado de este último país en la ONU, Jacobo Malik, fue descaradamente claro al explicar su postura:

México no parece haberse percatado de que no hay un solo miembro de las Naciones Unidas que no guarde esqueletos en su clóset. Si empezamos a exhibirlos... el resultado podría ser desastroso. .33

No fueron consideraciones de política exterior únicamente las que movieron al gobierno echeverrista a enfrascarse en la disputa contra Franco. Había también otros motivos. De politica interna y de índole personal. A la distancia resulta claro que el episodio español formó parte de una política internacional que tenía como uno de sus objetivos legitimar al sistema politico mexicano, por la vía de allegarse la simpatía de ciertos sectores, como la izquierda, la intelectualidad, la academia y los estudiantes. Formó parte de su tercermundismo, de su acercamiento con Chile, de su visita a países del campo socialista y de su confrontación discursiva contra las grandes potencias. En este caso fue la condena a un régimen considerado dictatorial, conservador y de derecha, que viola-

52 Ibid., p. 1.

53 Citado en Proceso, núm. 15, 12 de febrero, 1977 , p. 53. ba continuamente los derechos humanos. Las ejecuciones franquista fueron, de esta suerte, una coyuntura apropiada para desplegar de nueva cuenta acciones que se inscribían en esta nueva línea de la política exterior mexicana.

Otra motivación fue un anhelo personal de Echeverría: llegar a ser el secretario general de la ONU. En repetidas ocasiones negó tal pretensión, pero las evidencias mostraban lo contrario. En su quinto informe de gobierno aludió directamente al tema. Dijo en esa ocasión que debido a su "intensa actividad internacional" se había comentado la posibilidad de su candidatura a aquel cargo, pero "de manera inequívoca" declaró que ninguno de sus actos respondía a tal afán. ${ }^{54}$ Sin embargo, el mismo día del informe citado, varias personalidades internacionales, que habian sido invitadas al acto, formularon algunas declaraciones en un sentido distinto, al término de éste. Enrique Iglesias, secretario ejecutivo de la Comisión Económica para América Latina, expresó que la oNU necesitaba "de líderes como el presidente de México, para cumplir con la función histórica para la que fue creada". Alejandro Orfila, secretario general de la Organización de los Estados Americanos, señaló por su parte que el presidente Echeverría era un hombre "de mucho valor" que debía estar "al frente de las Naciones Unidas". 55 Y el día 5 de septiembre, El Nacional informó,

\footnotetext{
54 "Quinto informe de gobierno, 1975", Archivo Histórico Diplomático Mexicano, 1990, p. 52.

${ }^{55}$ El Nacional, 3 de sep., 1975, p. 1 y 8.
} 
a ocho columnas en primera plana, que Costa Rica postulaba a Echeverría para secretariogeneral de la ONU, pues según el canciller Gonzalo Facio tenía "grandes posibilidades" de ser electo. El secretario de Relaciones Exteriores, Emilio O. Rabasa, desde Nueva York afirmó que en la sede de la ONU existía un "clima favorable" a la candidatura del presidente mexicano a la secretaría general del organismo y citó como ejemplo la declaración "espontánea y generosa" del embajador costarricense Facio; aclaró no obstante que Echeverría no haría campaña ni promovería su candidatura. Pero continuó con el tema: dijo que los mexicanos debían sentirse orgullosos de que el número de delegados que expresaban su apoyo a la candidatura "de forma espontánea" era cada vez mayor. Rabasa explicó que la candidatura de Echeverría había surgido en "el seno de países del tercer mundo", como consecuencia de la "infatigable actividad desplegada por el presidente en el plano internacional y de su militancia en favor de los países subdesarrollados". 56

No era raro, por tanto, que el enfrentamiento con España haya formado parte de la estrategia de promoción de la candidatura de referencia. Pero las cosas fallaron también en este nivel. Cuando se discutía en la ONU la solicitud de expulsión de España, un diplomático de quien no se dijo su nombre respondió, al preguntársele sobre la candidatura de Echeverría, que éste "la echó a perder" ${ }^{57}$ Es decir, que la estrategia falló: quizá la posición de

56 Ibid., 5 y 6 de sep., 1975, pp. 1 y 7.

57 lbid., 30 de septiembre, 1975, p. 4.
México ante España abonó la idea de cierto radicalismo del presidente mexicano, que por lo demás ya se encontraba plenamente instalada en la mente de los gobernantes y diplomáticos de los países desarrollados.

La petición mexicana de expulsión de España de la ONU fue un despropósito, una acción mal calculada en términos políticos y débilmente formulada en términos jurídicos, y una contradicción en sus planteamientos. Sobre eso último, varios comentaristas señalaron la incapacidad o la negativa de Echeverría para distinguir entre el gobierno franquista y el pueblo español. El gobierno de Díaz Ordaz, por boca de su canciller Antonio Carrillo Flores, había señalado en 1970 que independientemente del afecto que existía entre los pueblos de México y España, las relaciones diplomáticas entre ambos países no cambiarían, pues seguirían sosteniéndose relaciones con el gobierno en el exilio. Carrillo Flores señaló en aquella ocasión que existian relaciones monetarias, comerciales y "comprensión de pueblo a pueblo" y una "cordialidad muy clara", y no obstante no habrían de establecerse vínculos formales con el gobierno de Franco. 58

Parecía clara, así, la distinción entre el pueblo y el gobierno españoles. Un mes antes de la carta de Echeverría, las delegaciones del Banco de España y del Banco de México se habían reunido en la capital mexicana para examinar el desarrollo del intercambio comercial entre ambos países durante el

58 Centro Republicano Español de México, 1978 , p. 401. 
año de 1974. Según datos del Ministerio de Comercio español, México había exportado a España bienes y servicios por un valor de 59.9 millones de dólares, mientras que España lo había hecho por un valor de 61.8 millones. La información oficial al respecto consignó que las dos delegaciones habían constatado "con satisfacción" el notable incremento del comercio bilateral y que hasta la fecha se habían creado en México doce empresas de capital mixto hispano-mexicano. 59

Las relaciones entre ambos países, como se puede ver, eran fluidas y constantes, a pesar de la falta de vínculos diplomáticos. Existían planes, incluso, para continuarlas en lo que restaba de ese año de 1975 y en el siguiente. Empresarios editoriales españoles se encontraban realizando gestiones en México desde junio de 1975 para tratar de suprimir un impuesto arancelario que, en su visión, les restaba posibilidades en la exportación de libros y publicaciones. Habían ya realizado varias reuniones en México con representantes de la industria editorial mexicana. Por otro lado, se tenía prevista la asistencia de una importante delegación española, presidida por el director general de Industrias Siderometalúrgicas, al IX Congreso Anual del Instituto Internacional del Hierro y del Acero que se celebraría en la ciudad de México los días 13, 14 y 15 de octubre. Una agencia española especializada ya había hecho circular entre empresarios de España una lista de probables clientes mexicanos in-

59 España, Oficina de Información Diplomática, núm. 25, agosto de 1975, p. 4. teresados en productos españoles. Y en agosto, el Consejo de Ministros español había autorizado a dos empresas, Industrias La Fuente, S.A. de Zaragoza y Sinerkao, S.A. de Barcelona, para efectuar inversiones en dos sociedades mexicanas, Super Diesel, S.A. y Quimikao, S.A., por valor de 11800000 y 13680000 pesetas respectivamente. ${ }^{60}$

Por otra parte, se celebró la edición 43 de la Feria Internacional de Muestras en Barcelona, del 3 al 12 de junio, a la que asistió una delegación de México. Al mes siguiente, en julio, se llevó a cabo un homenaje que la alcaldía de Madrid hizo al compositor mexicano Agustín Lara, en el que se le levantó un monumento en el barrio de "La Corrala". Presidió el acto el alcalde madrileño y participaron "doscientos charros mexicanos" y el cantante Pedro Vargas, quien apareció muy sonriente en la fotografia, abrazado del alcalde. ${ }^{61}$

Las relaciones eran pues cordiales. El diferendo las enturbió. En la manifestación que se llevó a cabo en Madrid, en defensa de España y del gobierno franquista, se produjeron expresiones ofensivas hacia los mexicanos, a los que se llamó "pobres in. dios". La xenofobia llegó también a México. Un editorialista de Excélsior tocó el tema en su colaboración del 11 de octubre. En ella señaló que la ofensa había provenido no del pueblo es-

${ }^{60}$ Véanse los números 137,140 y 141 del "Suplemento Noticioso DIA-Z" de Mercado Común Internacional, correspondientes a los meses de junio, julio y agosto de 1975.

61 España, Oficina de Información Diplomática, núms. 22 y 24, mayo y julio de 1975.

Marco antonio Landavazo Arias 
pañol sino de "franquistas exaltados, soberbios, ignorantes y fanáticos, muy a gusto con la barbarie medieval" en que vivían. Pero después de atacar a los "franquistas", el articulista se lanzó contra los españoles en general: los mexicanos habían sido al principio efectivamente unos "pobres indios", pero desde 1810 "dejamos de serlo", cuando las matanzas de españoles en Valladolid, Guanajuato, Guadalajara y Acapulco en tiempos de Hidalgo y Morelos; cuando la expulsión de españoles durante la presidencia de Vicente Guerrero; cuando la derrota de la expedición de reconquista de Barradas en Tampico. ${ }^{62}$ Para el comentarista, así, el dejar de ser pobres indios pasaba por la muerte, la expulsión, la vejación de los españoles. Nada más.

Las dudas se imponen. México alegaba congruencia con una política tradicional frente a España, pero por mucho tiempo se permitieron y aun alentaron las relaciones informales con ese país, bajo el argumento de que eran relaciones entre los dos pueblos. El régimen franquista fue considerado desde sus inicios una dictadura y ya antes de septiembre de 1975 había ejecutado a oposicionistas. ¿Por qué entonces hasta esa fecha se consideró necesario romper los vínculos que antes no se habían visto como negativos? Para "aislar" a España y "precipitar" la caída del gobierno, confesó Echeverria. Pero si ello hubiera sido así, ¿por qué no se hizo antes? Y aun cuando ése hubiera sido el objetivo, los resul-

62 Excélsior, 11 de octubre, 1975, artículo de Abraham López, p. 6. tados fueron diferentes: en realidad, la reacción mexicana propició condiciones para que Franco reforzara su autoridad y enturbió relaciones que habían sido cordiales.

El fracaso podría ser el rasgo principal de la solicitud echeverrista, pues no logró ninguno de sus objetivos, ocultos o declarados. No precipitó la caída de Franco, pues ésta se debió a la gravedad de su salud y su muerte; no sirvió para que Echeverría alcanzara la candidatura a la secretaría general de la ONU, pues más bien obró en contra de ese propósito; no ayudó a legitimar al gobierno, pues desató una discusión al interior del país y muchas de las voces críticas la cuestionaron. Pero sí logró, al menos, una contribución: la de ayudarnos a entender un poco más acerca de las relaciones entre política exterior y política interior, en una coyuntura propia de un país que, como México, tiene la característica de poseer un sistema político en el que el presidente ha gozado de amplias facultades políticas. Echeverrría simplemente las usó.

\section{FueNTES: PERIÓdICOS Y}

REVISTAS

-Excélsior, México, D.F. - El Nacional, México, D.F. -España al Día, México, D.F. - $A B C$, Madrid. -Proceso, México, D.F. -Siempre, México, D.F. -Time, Nueva York.

-España, Madrid. celona.

Mercado Común Internacional, Bar- 


\section{BIBLIOGRAFÍ}

-Archivo Histórico-Diplomático Mexicano, 20 años de política exterior a través de los informes presidenciales. 1970-1990, Secretaría de Relaciones Exteriores, México, 1990.

-Carpizo,Jorge, Elpresidencialismo mexicano, Siglo XXI Editores, México, 1987.

- Centro Republicano Español de México, Por España, contra Franco, Mensaje a los españoles con copia al resto de la opinión mundial, Centro Republicano Español, México, 1975. , México y la república española. Antología de documentos, 1931. 1977, Centro Republicano Español, México, 1978.

Cola Alberich, Julio, "Diario de acontecimientos referentes a España durante los meses de agosto y septiembre de 1975", Revista de Política Internactonal, núm. 141, sept.-oct., 1975.

"Diario de acontecimientos referentes a España durante los meses de octubre y noviembre de 1975", Revista de Política Internacional, núm. 142, nov.dic., 1975.

-Cosio Villegas, Daniel, El estilo personal de gobernar, Joaquín Mortiz, México, 1974.

-Chabat, Jorge, "Condicionantes del activismo de la política exterior mexicana (1960-1985)" en Garza Elizondo (comp.), Fundamentos, 1986, pp. 89-108.

-De la Pedraja, Daniel y Luisa Treviño Huerta, México y España. Transición y cambio, Joaquín Mortiz, México, 1983.

-Diaz, Luis Miguel y Jaime G. Martini (comps.), Relaciones diplomáticas México-España (1821-1977), Porrúa, México, 1977.

-García Robles, Alfonso, Seis años de la política exterior de México, 1970-1976,
Secretaria de Relaciones Exteriores, México, 1976. do de Cultura Económica, México, 1977.

-Garza Elizondo, Humberto (comp.)

Fundamentos y prioridades de la política exterior de México, El Colegio de México, México, 1986.

-Green, Rosario, "La política exterior del nuevo régimen", en Continuidades y cambio en la política exterior de México, El Colegio de México, México, 1977.

-Griepenburg, Rüdiger, "Relaciones entre la política interior y exterior", en Wolfgang Abendroth y Kurt Lenk (comps.), Introducción a la ciencia política, Anagrama, Barcelona, 1971.

-Heredia, Blanca, "La relación entre política interna y política exterior: una definición conceptual. El caso de México" en Garza Elizondo (comp.), Fundamentos, 1986, pp. 115-133.

-Lacharrière, René, Etudes surla theorie democratique, París, 1964.

-Ojeda, Mario, Alcances y límites de la política exterior de México, El Colegio de México, México, 1984.

-Rabasa, Emilio O., "Apuntes para un estudio de las relaciones internacionales de México en los últimos 25 años", Relaciones Internacionales, vol. $\mathrm{IV}$, núm. 15 , oct.-dic., 1976.

-Shapira, Yoam, "La política exterior de México bajo el régimen de Echeverria: retrospectiva", Foro Internacional, núm. 19,1978 , pp. 62-91.

-United Nations, Yearbook of the United Nations. 1975, vol. 29, United Nations, Nueva York, 1978.

-Valero, Ricardo, "La política exterior de México: el proyecto de Echeverría", en Lecturas de política exterior de México, $\mathrm{El}$ Colegio de México, México, 1979, pp. 77. 108. 